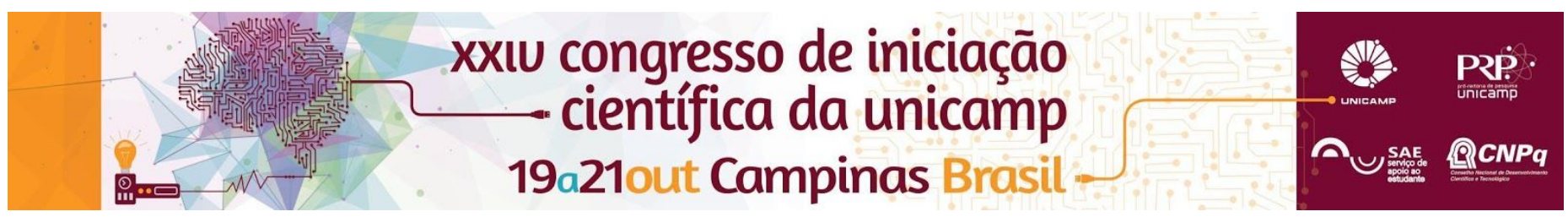

\title{
Parametrização e validação de modelos matemáticos computacionalmente eficientes e biologicamente plausíveis de neurônios motores
}

\section{Ali S. F. Silva*, Leonardo A. Elias}

\section{Resumo}

O objetivo deste estudo foi desenvolver modelos matemáticos computacionalmente eficientes e biologicamente plausíveis de neurônios motores de vertebrados. Modelos de neurônios motores de diferentes tipos (S, FR e FF) foram implementados em linguagem de programação Python utilizando-se bibliotecas do simulador Neuron. Os modelos foram parametrizados e validados sistematicamente tendo como base dados reportados na literatura experimental.

\section{Palavras-chave:}

Eletrofisiologia, Motoneurônio, Neurociência Computacional

\section{Introdução}

Um dos elementos fundamentais no controle do movimento é o neurônio motor, cuja atividade é responsável pela geração da força dos músculos esqueléticos. Em uma dada tarefa motora, diferentes tipos de neurônios motores são recrutados. Três tipos básicos foram caracterizados em estudos experimentais realizados em gatos: i) tipo $S$ (slow), que inervam fibras musculares lentas e resistentes à fadiga; ii) tipo FR (fatigue resistant), que inervam fibras rápidas, porém, resistentes à fadiga; e iii) tipo FF (fast fatigable), que inervam fibras rápidas e fatigáveis ${ }^{1}$.

A modelagem matemática e a simulação computacional têm auxiliado no entendimento da eletrofisiologia motoneuronal. Nesse projeto, foram desenvolvidos modelos matemáticos computacionalmente eficientes e biologicamente plausíveis de neurônios motores de vertebrados. Os comportamentos observados a partir das simulações destes modelos foram comparados com dados reportados na literatura experimental.

\section{Resultados e Discussão}

Os modelos foram implementados em linguagem de programação Python em conjunto com bibliotecas do simulador Neuron ${ }^{2}$. Do ponto de vista morfológico, os modelos foram representados por dois compartimentos cilíndricos, um representando o soma e outro a arborização dendrítica ${ }^{3}$. Em ambos os compartimentos, foram incluídas as propriedades passivas da membrana (capacitância da membrana e resistência de fuga). No soma, foram incluídos canais iônios ativos de $\mathrm{Na}^{+}$, rápido de $\mathrm{K}^{+}$e lento de $\mathrm{K}^{+}$. Os dois primeiros canais são responsáveis pela geração do potencial de ação e o último fornece a dinâmica da hiperpolarização pós-potencial de ação (AHP, do inglês afterhyperpolarization $)^{4}$. O compartimento dendrítico foi considerado passivo, ou seja, sem canais iônicos dependentes do potencial de membrana.

Correntes em pulso ou em degrau foram injetadas no compartimento somático de cada modelo para determinar características básicas, como a amplitude do potencial de ação, a resistência de entrada, reobase, amplitude e duração da AHP. Com os parâmetros geométricos e eletrotônicos adotados, todos os modelos apresentaram características similares a observações experimentais ${ }^{5,6}$. Para validar os modelos, foram estimadas as relações entre a frequência de disparos de potenciais de ação $(f)$ e a magnitude da corrente em degrau injetada no soma $(I)$. A Figura 1 mostra que as curvas $f$-l dos modelos são aproximadamente lineares (vide ajustes lineares). Os ganhos $(\mathrm{Hz} / \mathrm{nA})$ são compatíveis com os dados reportados em outros estudos experimentais ${ }^{7}$.

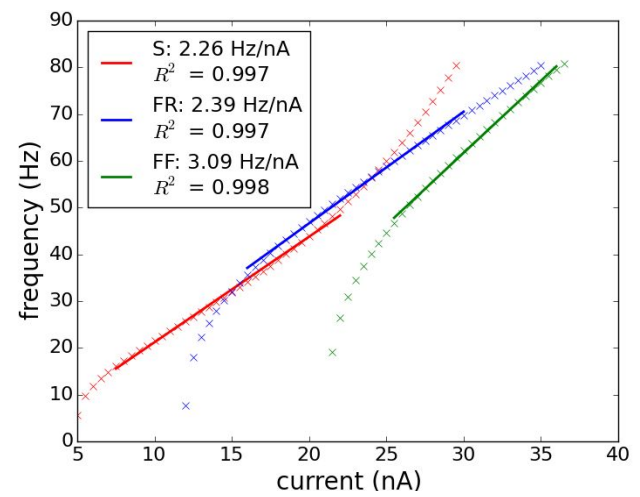

Figura 1. Relações frequência-corrente $(f-l)$ para os três modelos de neurônios motores ( $S$, FR e FF). As curvas cheias representam ajustes lineares, cujos coeficientes de determinação $\left(R^{2}\right)$ são apresentados na legenda.

\section{Conclusões}

Tendo em vista que os modelos desenvolvidos neste estudo apresentaram comportamentos similares àqueles observados em estudos experimentais com neurônios motores de vertebrados, estudos futuros poderão utilizá-los para investigar o controle da força muscular.

\section{Agradecimentos}

ASFS foi bolsista de iniciação científica do PIBIC/CNPq.

\footnotetext{
1. Burke, R. E. J. Physiol. 1967, 193, 141.

2. Hines, M. L.; Davison, A. P.; Muller, E. Front. Neuroinform. 2009, 3, 1.

3. Cisi, R. R.L.; Kohn, A. F. J. Comput. Neurosci. 2008, 25, 520.

4. Traub, R. D. Biol. Cybern. 1977, 25, 163.

5. Gustafsson, B.; Pinter, M. J. J. Physiol. 1984, 357, 453.

6. Zengel, J. E. et al. J. Neurophysiol. 1985, 53, 1323.

7. Kernell, D. Acta Physiol. Scand. 1965, 65, 65.
} 